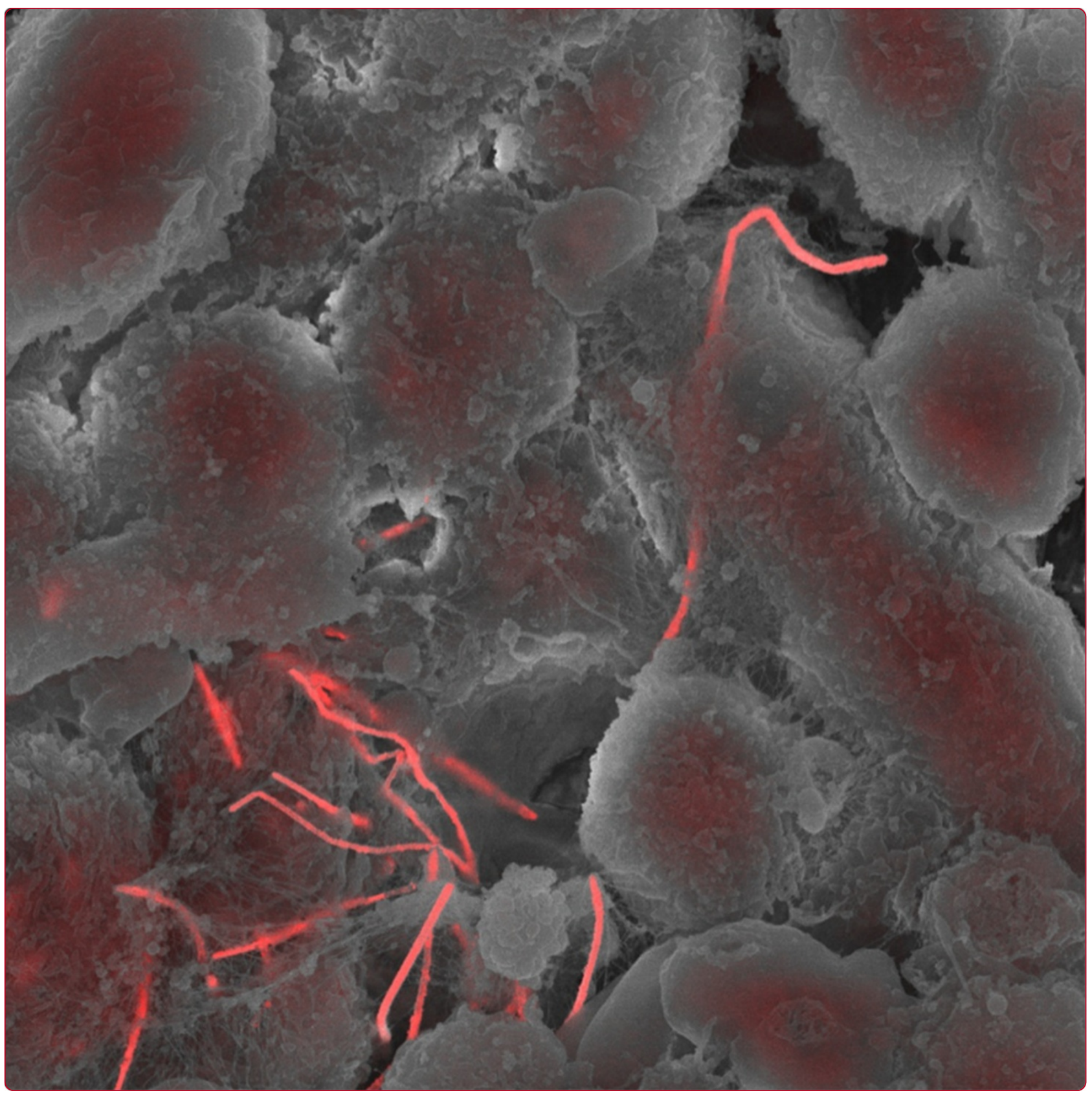

Use of back-scatter electron signals to visualise cell/ nanowires interactions in vitro and in vivo; frustrated phagocytosis of long fibres in macrophages and compartmentalisation in mesothelial cells in vivo

Schinwald and Donaldson 


\title{
Use of back-scatter electron signals to visualise cell/nanowires interactions in vitro and in vivo; frustrated phagocytosis of long fibres in macrophages and compartmentalisation in mesothelial cells in vivo
}

\author{
Anja Schinwald and Ken Donaldson
}

\begin{abstract}
Background: Frustrated phagocytosis has been stated as an important factor in the initiation of an inflammatory response after fibre exposure. The length of fibrous structures has been linked to the potential of fibres to induce adverse health effects for at least 40 years. However, we only recently reported for the first time the threshold length for fibre-induced inflammation in the pleural space and we implicated frustrated phagocytosis in the pro-inflammatory effects of long fibres. This study extends the examination of the threshold value for frustrated phagocytosis using well-defined length classes of silver nanowires (AgNW) ranging from 3-28 $\mu \mathrm{m}$ and describes in detail the morphology of frustrated phagocytosis using a novel technique and also describes compartmentalisation of fibres in the pleural space.

Methods: A novel technique, backscatter scanning electron microscopy (BSE) was used to study frustrated phagocytosis since it provides high-contrast detection of nanowires, allowing clear discrimination between the nanofibres and other cellular features. A human monocyte-derived macrophage cell line THP-1 was used to investigate cell-nanowire interaction in vitro and the parietal pleura, the site of fibre retention after inhalation exposure was chosen to visualise the cell- fibre interaction in vivo after direct pleural installation of AgNWs.

Results: The length cut-off value for frustrated phagocytosis differs in vitro and in vivo. While in vitro frustrated phagocytosis could be observed with fibres $\geq 14 \mu \mathrm{m}$, in vivo studies showed incomplete uptake at a fibre length of $\geq 10 \mu \mathrm{m}$. Recently we showed that inflammation in the pleural space after intrapleural injection of the same nanofibre panel occurs at a length of $\geq 5 \mu \mathrm{m}$. This onset of inflammation does not correlate with the onset of frustrated phagocytosis as shown in this study, leading to the conclusion that intermediate length fibres fully enclosed within macrophages as well as frustrated phagocytosis are associated with a pro-inflammatory state in the pleural space. We further showed that fibres compartmentalise in the mesothelial cells at the parietal pleura as well as in inflammatory cells in the pleural space.

(Continued on next page)
\end{abstract}

\footnotetext{
* Correspondence: ken.donaldson@ed.ac.uk

Centre for Inflammation Research, Queen's Medical Research Institute, MRC/ University of Edinburgh, 47 Little France Crescent, Edinburgh EH16 4TJ, UK
} 
(Continued from previous page)

Conclusion: BSE is a useful way to clearly distinguish between fibres that are, or are not, membrane-bounded. Using this method we were able to show differences in the threshold length at which frustrated phagocytosis occurred between in vitro and in vivo models. Visualising nanowires in the pleura demonstrated at least 2 compartments - in leukocyte aggregations and in the mesothelium - which may have consequences for long term pathology in the pleural space including mesothelioma.

Keywords: Backscatter scanning electron microscopy (BSE), Frustrated phagocytosis, THP-1 macrophages, Pleural macrophages, Parietal pleura mesothelium

\section{Background}

The toxicology of fibres is a sub-specialty of particle toxicology developed in response to the asbestos experience [1] but whose tenets have been used to quantify the hazards from vitreous fibres [2] organic fibres such as p-aramid [3] and most recently nanofibres [4,5]. Current understanding of the fibre hazard is based on the 'fibre pathogenicity paradigm' which has predictive power and is the most robust structure/ toxicity relationship in particle toxicology. The paradigm identifies thinness, length and biopersistence as the 3 features that determine the pathogenic potential of any fibre sample [5]. Thinness determines respirability, that is the likelihood that a fibre penetrates the respiratory tract beyond the ciliated airways [3] where most damage is likely to occur, whilst biopersistence determines whether the fibre will retain its structure integrity i.e. fibrous shape, during residence in the lung. If the fibre is composed of soluble components that are leached from the fibre under the conditions it encounters in vivo, then the fibre is likely to become weakened, break and become part of the short fibre pool. Short fibres are not pathogenic in the fibre sense, although they may have harmful effects as particles, whilst long fibres do cause fibre-type pathogenicity; this length-dependent pathogenicity has been demonstrated in numerous studies in vivo [6-8] and in vitro [9-11].

One major arbiter of length-dependent pathogenic effect is the alveolar macrophage and pleural macrophage whose normal function is to phagocytose fibres and clear them. Because of the unusual aerodynamics of fibres, extremely long fibres penetrate and deposit beyond the ciliated airways [3]. Macrophages that attempt to phagocytose long fibres cannot enclose them leading to 'frustrated phagocytosis' as shown diagrammatically in Figure 1; in contrast short fibres are fully enclosed in the phagosomes (Figure 1).

We recently reported length-dependent effects of a range of fibres including asbestos [8], carbon nanotubes $[12,13]$, silver nanowires (AgNW) [14] and nickel nanowires (NiNW) [11] at the peritoneal and pleural mesothelial surfaces. All of these fibre types appear to comply with the fibre pathogenicity paradigm with length-dependent effects in the pleural space as a result of retention at stomata $(3-10 \mu \mathrm{m}$ in diameter) on the parietal pleura and frustrated phagocytosis. These data show persuasively that the length threshold for pleural retention of any fibres is $5 \mu \mathrm{m}$ and that fibre shorter than this threshold are not retained and do not cause inflammation [14].

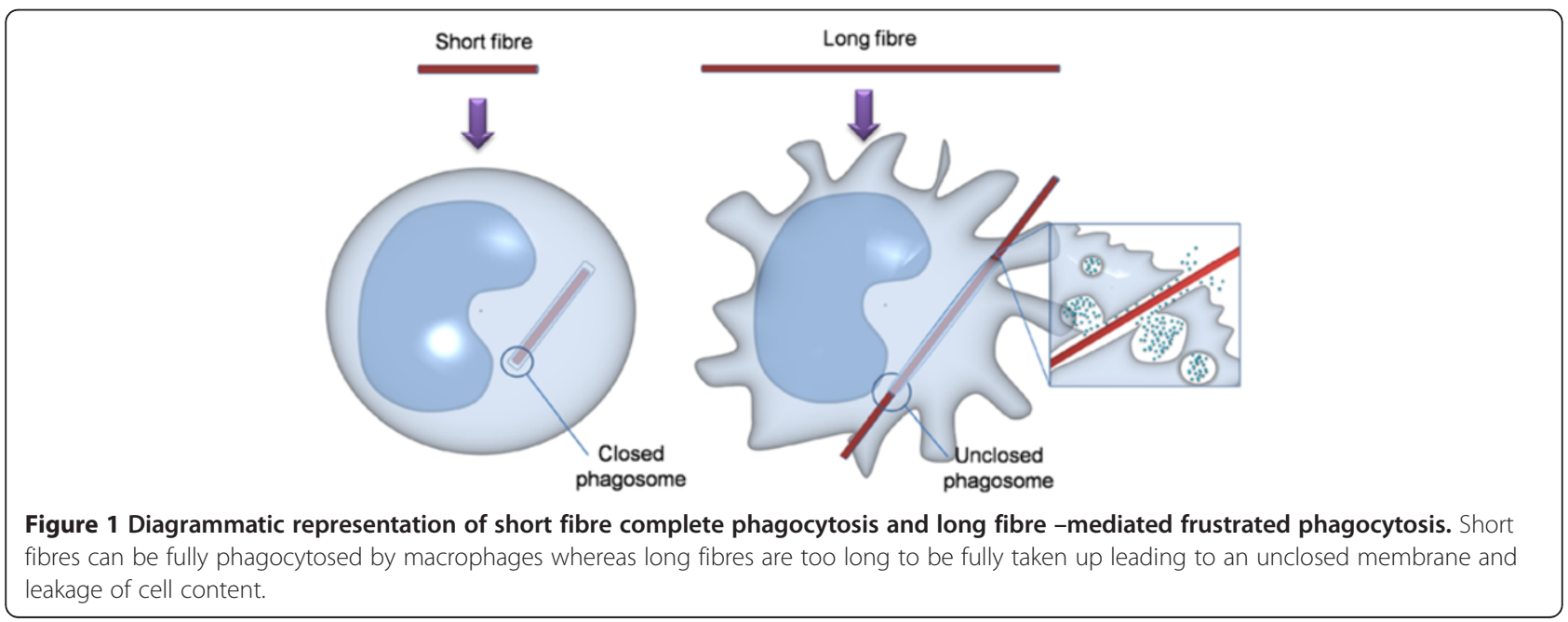




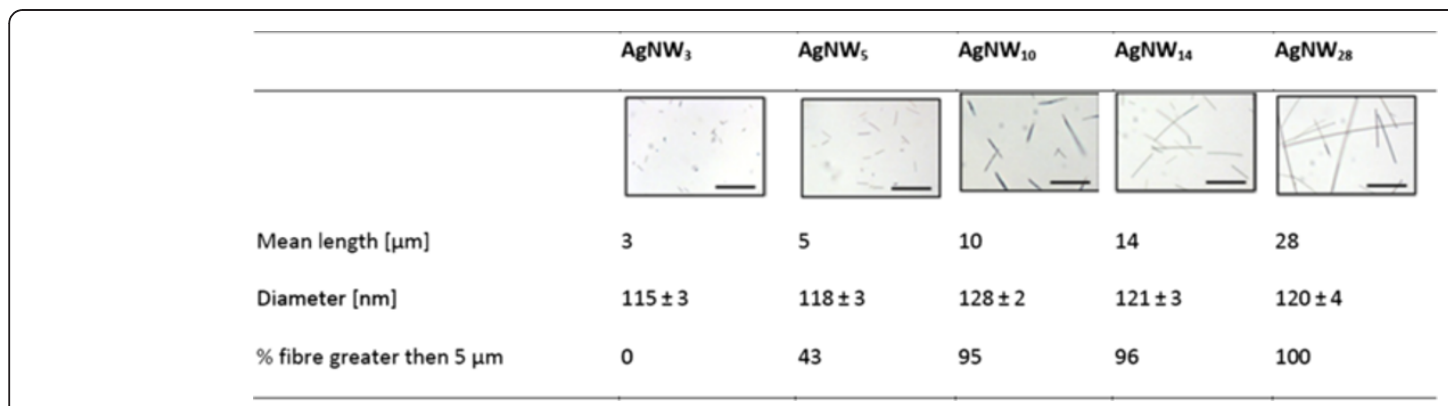

Figure 2 Characteristics of AgNW panel. Light microscopy images of AgNW panel in 0.5\% BSA/saline. Scale bar $20 \mu \mathrm{m}$.

Whilst we evoked frustrated phagocytosis in the proinflammatory effects, we also noted that intermediate $5 \mu \mathrm{m}$ length fibres, were fully enclosed by macrophages but were pro-inflammatory, as previously recorded [14]. Due to restrictions on space we could not fully explore the morphological basis of this new effect and here we extend these findings to fully characterise fibre length effects particularly frustrated phagocytosis in vitro and in vivo. We utilised the technique of backscatter electron microscopy in particular to investigate this phenomenon. We also describe the retention of fibres in the parietal mesothelial layer, an anatomical region not hitherto identified a retention compartment for fibres.

\section{Results}

\section{AgNW panel}

Characteristic of the AgNW panel are summarised in Figure 2. The images illustrate the uniform distribution of the AgNWs with no aggregation being present. Complete characterisation of the AgNW panel was described previously by Schinwald et al. [14].

\section{Membrane integrity and metabolic activity in the in vitro model}

The in vitro experiments were based on a treatment dose which was non/low-toxicity to THP-1 cells in culture adjusted for each fibre length to produce approximately the same fibre number (Table 1 ). The $2 \mu \mathrm{g} / \mathrm{cm}^{2}$ dose based on $\mathrm{AgNW}_{14}$ was determined by measuring

Table 1 Calculation for the mass adjustments for equalisation of number

\begin{tabular}{lll}
\hline $\begin{array}{l}\text { Length class } \\
{[\boldsymbol{\mu \mathrm { m } ]}}\end{array}$ & $\begin{array}{l}\text { Calculation to equalise for } \\
\text { the same fibre number }\end{array}$ & $\begin{array}{l}\text { Dose } \\
\left(\boldsymbol{\mu \mathbf { g } / \mathbf { c m } ^ { 2 } )}\right.\end{array}$ \\
\hline $\mathbf{3}$ & $3 / 14 \times 2$ & 0.4 \\
$\mathbf{5}$ & $5 / 14 \times 2$ & 0.6 \\
$\mathbf{1 0}$ & $10 / 14 \times 2$ & 1.4 \\
$\mathbf{1 4}$ & standard & 2.0 \\
$\mathbf{2 8}$ & $28 / 14 \times 2$ & 4.0 \\
\hline
\end{tabular}

the membrane integrity via the release of lactate dehydrogenase (LDH) into the supernatant and cell proliferation of the THP-1 cells after 24 hour treatment; however, $\mathrm{AgNW}_{28}$ caused a significant decrease in membrane integrity and loss of proliferation and metabolic activity (Figure 3A,B).

\section{Bright field microscopy of THP-1 cells after 4 hour exposure in vitro}

THP-1 cells were exposed to the panel of AgNWs for 4 hours and bright field images were taken using a $60 \times$ magnification. THP-1 cells completely phagocytose $\mathrm{AgNW}_{3}$ (Figure 4A) and $\mathrm{AgNW}_{5}$ (Figure 4B). The fibres were fully taken up as indicated by the yellow circle. $\mathrm{AgNW}_{10}$ were mostly phagocytosed with only a small percentage of fibre-ends protruding out of the cells as indicated by the red arrow (Figure 4C). Frustrated phagocytosis was observed after treatment with $\mathrm{AgNW}_{14}$ and $\mathrm{AgNW}_{28}$. In Figure 5d the black arrow indicates a fibre shared by two cells and another fibre only partly enclosed by the cell (red arrow Figure 4D and E).

\section{Characterisation of Cell/Nanowire interaction in vitro using BSE}

Backscatter electron microscopy (BSE) enabled us to visualise the interaction of THP-1 macrophage cells with AgNW. We mainly focused on the uptake/phagocytosis of the five different size categories of AgNW to identify the cut-off value, at which frustrated phagocytosis occurs in vitro. Figure 5A-E show differentiated THP-1 macrophages after 4 hour treatment with $\operatorname{AgNW}_{3}(\mathrm{~A}), \mathrm{AgNW}_{5}$ (B), $\operatorname{AgNW}_{10}(\mathrm{C}), \mathrm{AgNW}_{14}$ (D) and $\mathrm{AgNW}_{28}$ (E). In Figure $5 \mathrm{~A}$ one external $\mathrm{AgNW}_{3}$ can be seen (white arrow) and a few $\mathrm{AgNW}_{3}$ can be seen just underneath the surface of a macrophage as indicated by the black arrow (Figure 5A insert). After treatment with $\mathrm{AgNW}_{5}$, nanowires were fully taken up by macrophages as indicated by the white arrow (Figure 5B insert). A small proportion of cells showing incomplete uptake of $\mathrm{AgNW}_{10}$ fibres could be observed as indicated by the white arrow 

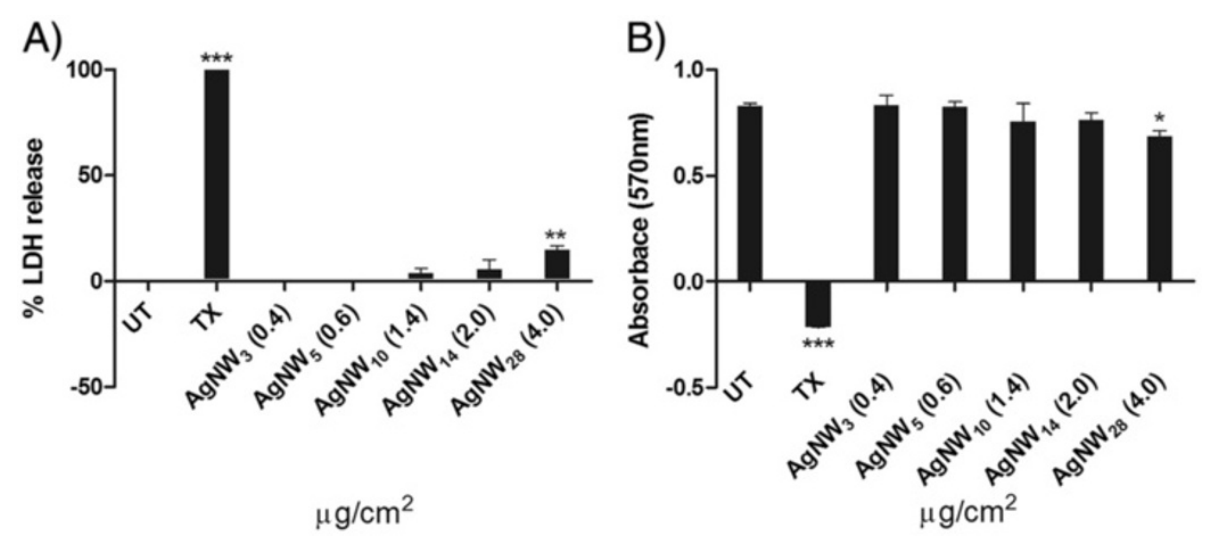

Figure 3 THP-1 membrane integrity and proliferation/metabolic activity. A) Measurement of membrane integrity plotted as \% LDH release based and positive and negative control. Only $\mathrm{AgNW}_{28}$ lead to a significant release of LDH into the supernantant. B) Proliferation and metabolic activity was measured using alamarBlue ${ }^{\circledast}$. Cell treated with $\mathrm{AgNW}_{28}$ showed decreased proliferation. Significance versus vehicle control ${ }^{*} \mathrm{P}<0.05$, **P $<0.01$. Data represent mean \pm s.e.m. of $n=5$.

(Figure 5C) however most of the fibres were membrane bound (black/white arrow) and therefore phagocytosed by the cells. Obvious frustrated phagocytosis could be observed from a nanowire length of $14 \mu \mathrm{m}$ (Figure 5D) and $28 \mu \mathrm{m}$ (Figure 5E). A much greater amount of AgNW was observed protruding through cells or shared between adjacent cells indicating frustrated phagocytosis (white arrow). The number of unphagocytosed fibres per cell was quantified and significantly increased with $\mathrm{AgNW}_{14}$ ( $\mathrm{p}>0.05)$ and $\mathrm{AgNW}_{28}(\mathrm{p}>0.001)$.

\section{In vivo}

\section{Uptake of AgNWs in pleural macrophages from pleural} lavage

In Figure 6A a macrophage is shown from a pleural lavage after treatment with $\mathrm{AgNW}_{3}$. The macrophage could readily phagocytose a number of short $(3 \mu \mathrm{m})$ AgNWs (Figure 6A). After treatment with $\mathrm{AgNW}_{5}$ (Figure 6B), again the nanowires were fully taken up by the pleural macrophages in the lavage fluid. However, $\mathrm{AgNW}_{10}(\mathrm{C}), \mathrm{AgNW}_{14}$ (D) and $\mathrm{AgNW}_{28}$ (E) could not
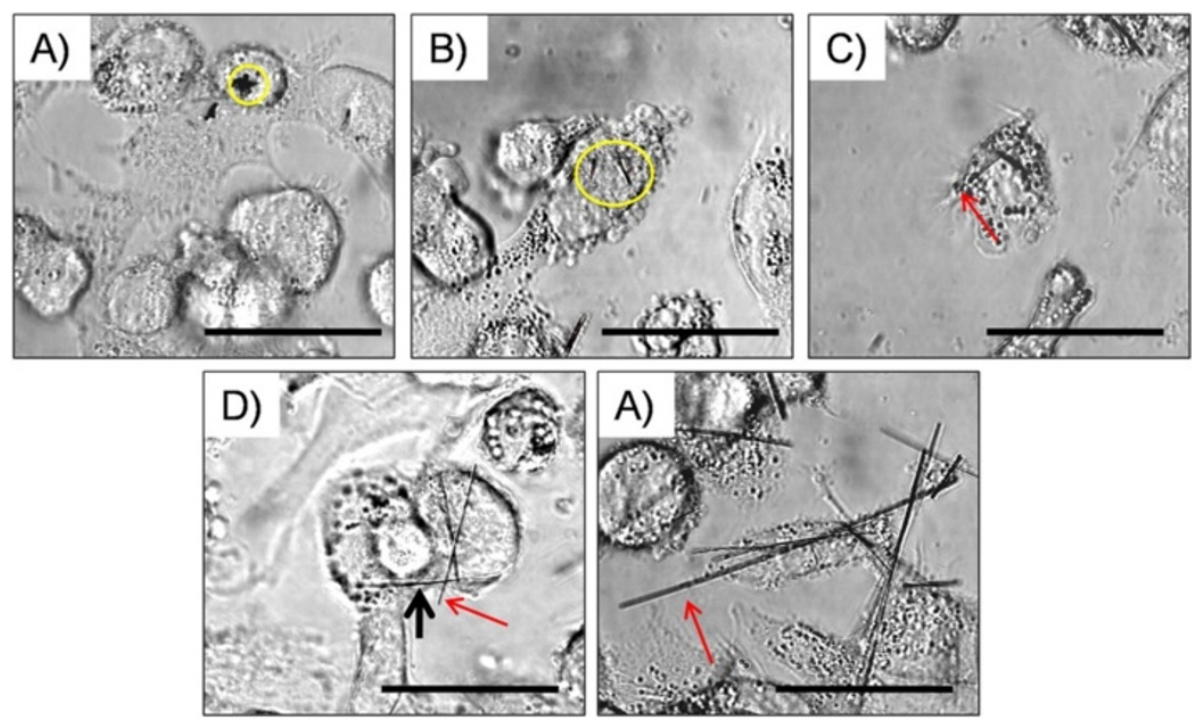

Figure 4 Bright-field microscope image of THP-1 cells treated with AgNWs. A) AgNW 3 and B) AgNW 5 were fully enclosed by the cell as indicated by the yellow circle. C) $A_{g N W}$ were mostly taken up, however a small number of fibres were not fully enclosed and fibre ends were protruding out of the cells as indicated by the red arrow. D) $\mathrm{AgNW}_{14}$ and $\left.\mathbf{C}\right) \mathrm{AgNW}_{28}$ caused frustrated phagocytosis. Red arrows indicate fibres partly taken up by THP-1 cells and the black arrow indicates sharing of a fibre between two adjacent cells. Scale bar $=20 \mu \mathrm{m}$. 

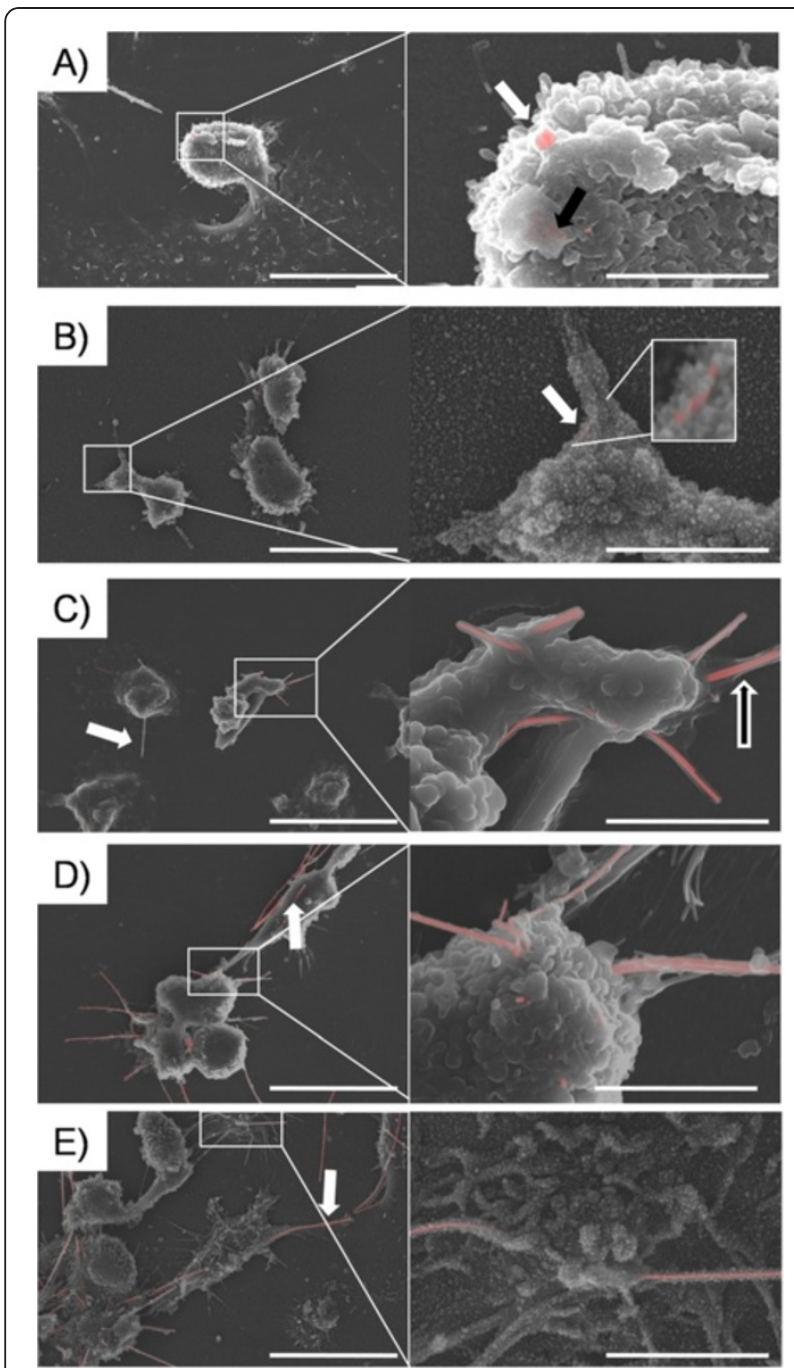

Figure 5 BSE images of differentiated THP-1 cells treated for 4 hours with AgNW. A) $\mathrm{AgNW}_{3}$ treated macrophages showed full phagocytosis of the nanowires. Only one nanowire could be visualised outside a cell (white arrow) and a few underneath the surface indicated by the black arrow. B) After $\mathrm{AgNW}_{5}$ treatment all nanowires were phagocytosed by cells after 4 hours (white arrow). C) A big proportion of $\mathrm{AgNW}_{10}$ appear membrane bound and therefore phagocytosed by cells (black/white arrow), however a few fibres could be seen protruding out of cells (white arrow). Frustrated phagocytosis was observed after $\mathrm{AgNW}_{14}$ (D) and $\mathrm{AgNW}_{28}(\mathbf{E})$ treatments, since most of fibres can be seen protruding out of the cells or shared between cells (white arrow and insert). BSE merged image with a scale bar of $10 \mu \mathrm{m}$ and $5 \mu \mathrm{m}$ for the inserts.

be fully phagocytosed by the cells anymore, leading to frustrated phagocytosis. Enlargement of the pleural macrophages (Figure 6D) could be observed. Data from the same animals as described here were utilised in Schinwald et al. [14] where details of the inflammatory effects accompanying these cellular changes can be obtained.

\section{Phagocytosis/frustrated phagocytosis in vivo on the parietal pleura surface 24 hour post exposure}

Backscatter scanning electron microscopy examination was carried out on the macrophage accumulations on the parietal pleura samples from mice injected with $\mathrm{AgNW}_{3}, \mathrm{AgNW}_{5}$ and $\mathrm{AgNW}_{10}$ at 24 hour post intrapleural instillation in order to examine the development of interaction between the mesothelial cell layer/ inflammatory cells on the surface. The dose of $5 \mu \mathrm{g}$ per mouse used in this study lead to a significant increase in inflammation after treatment with $\mathrm{AgNW}_{5}, \mathrm{AgNW}_{10}$, $\mathrm{AgNW}_{14}$ and $\mathrm{AgNW}_{28}$ as previously reported [14]. A dose response was performed by increasing the dose of $\mathrm{AgNW}_{3}$ up to $10 \mu \mathrm{g}$ which resulted in no significant increase in inflammation. The dose of $\mathrm{AgNW}_{5}$ was decreased to $1 \mu \mathrm{g}$ and $2.5 \mu \mathrm{g}$ whereby $2.5 \mu \mathrm{g}$ continuously showed significant inflammation [14]. $\mathrm{AgNW}_{3}$ treatment was chosen to investigate if any short fibre were retained in the pleural space after intrapleural injection even though no inflammatory response was observed. $\mathrm{AgNW}_{5}$ and $\mathrm{AgNW}_{10}$ treatments were chosen since both treatments lead to a significant increase in pleural inflammation however differ in their interactions with pleural macrophages [14]. No $\mathrm{AgNW}_{3}$ could be observed on the parietal pleura surface 24 hour post treatments confirming that short fibres are readily cleared from the pleural space. In contrast to $\mathrm{AgNW}_{3}$, both $\mathrm{AgNW}_{5}$ and $\mathrm{AgNW}_{10}$ lead to an aggregation of inflammatory cells on the surface of the parietal pleura with accumulation of nanowires within the lesion area (Figure $7 \mathrm{~A}, \mathrm{C}$ ). Most $\mathrm{AgNW}_{5}$ were fully phagocytosed by pleural macrophages (Figure 7A, B and insert, stars). In comparison, $\mathrm{AgNW}_{10}$ showed a number of fibres only partly phagocytosed and therefore leading to frustrated phagocytosis (Figure 7C,D white arrow). Some $\mathrm{AgNW}_{5}$ and $\mathrm{AgNW}_{10}$ were not taken up by macrophages as indicated by the yellow arrows (Figure 7A,C). By looking at the surface with higher magnification unclosed membrane could be visualised in pleural macrophages phagocytosing $\mathrm{AgNW}_{10}$ (Figure $7 \mathrm{D}$ and insert, black arrows).

\section{Phagocytosis/frustrated phagocytosis in vivo on the parietal pleura surface 1 week post exposure}

BSEM of parietal pleura after 1 week treatment with $\mathrm{AgNW}_{5}$ are shown in Figure $8 \mathrm{~A}, \mathrm{~B}, \mathrm{C}$ and $\mathrm{AgNW}_{10}$ in Figure 8D,E,F. By 1 week, $\mathrm{AgNW}_{5}$ started to lose their integrity, presumably in the acidic conditions within a phagosome as seen in Figure 8A,B indicated by the black arrow. Non-dissolved fibres overlying the mesothelial cell layer appear intact in their morphology (Figure 8B, white arrow). Ghost-like structures of nanofibres which are covered by microvilli (Figure 8B,C star) could be seen. $\mathrm{AgNW}_{10}$ could be found either in accumulations of inflammatory cells which appeared denser and more 


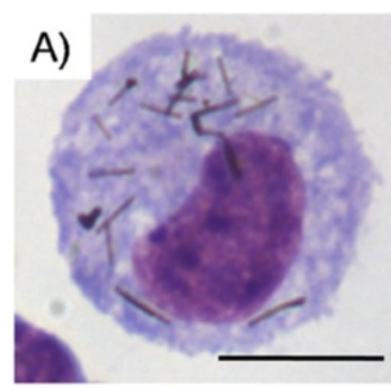

B)

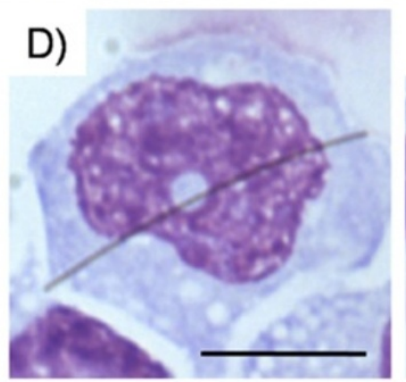

E)

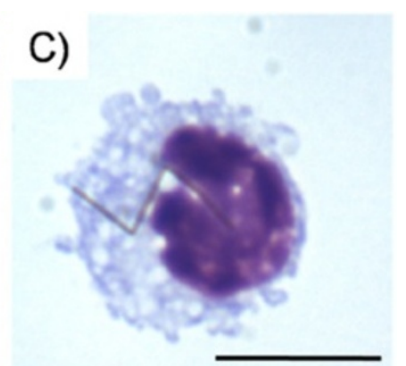

C)

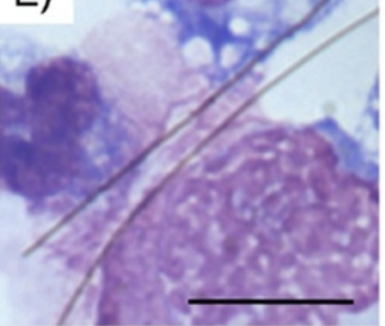

Figure 6 Representative cytospin images of lavaged cells from the pleural space after 24 hour treatment with AgNWs. A) $\mathrm{AgNW}_{3}$ inside a pleural macrophage showing complete phagocytosis. B) Pleural macrophage with a fully phagocytosed $\mathrm{AgNW}_{5}(\mathbf{B})$ and $\mathrm{AgNW}_{10}(\mathbf{C})$. D) $\mathrm{A}$ pleural macrophage with increased cell size to phagocytose AgNW ${ }_{14}$. E) Frustrated phagocytosis after AgNW 28 exposure. 3 macrophages sharing 2 long fibres. All images are shown at 100x magnification with a $10 \mu \mathrm{m}$ scale bar.
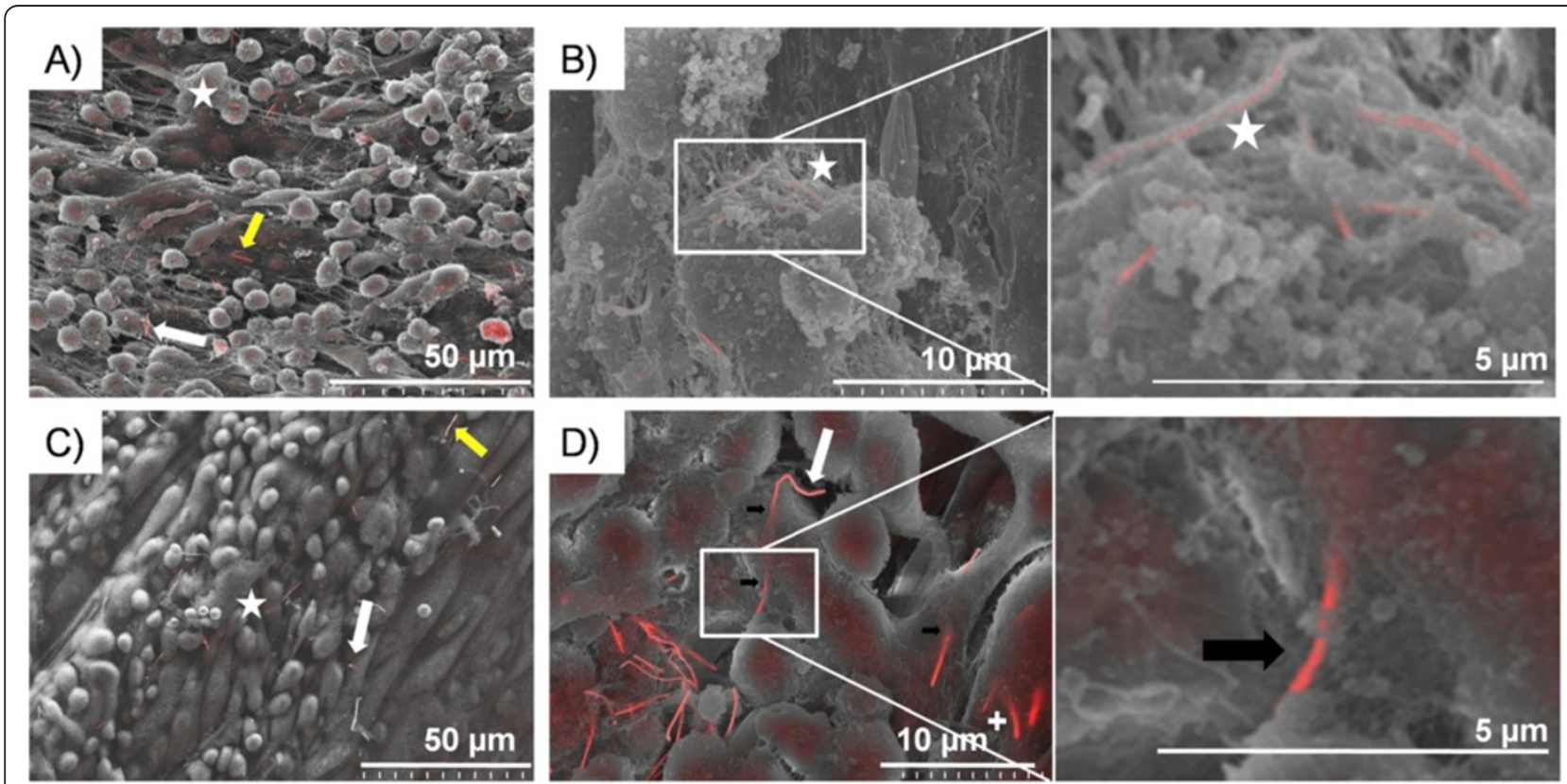

Figure $\mathbf{7}$ Images of the parietal pleura surface $\mathbf{2 4}$ hour post pleural instillation of $\mathbf{A g N W}_{\mathbf{5}}$ and $\mathbf{A g N W}_{10}$. Overview of the lesion area on the surface of the parietal pleura with $\operatorname{AgNW}_{5}(\mathbf{A})$ and $\mathrm{AgNW}_{10}(\mathbf{C})$. The yellow arrow indicates a nanowire which is not taken up by inflammatory cells whereas the star indicates a fibre that is fully phagocytosed but can be visualised underneath the surface of the cell. The white arrow indicates nanowires which are protruding out of cells. B) This figure shows AgNW 5 that are fully phagocytosed by pleural macrophages but can be visualised underneath the surface as indicated by the star. D) AgNW 10 is causing frustrated phagocytosis in a macrophage in the centre of the image. The unclosed cell membrane is indicated by the black arrows and exposed fibre surface is indicated by the white arrow. The cross on the lower right of the image indicates fibres which are largely internalised but whose tips rise vertically to penetrate the cell surface adjacent to the other long fibre. 

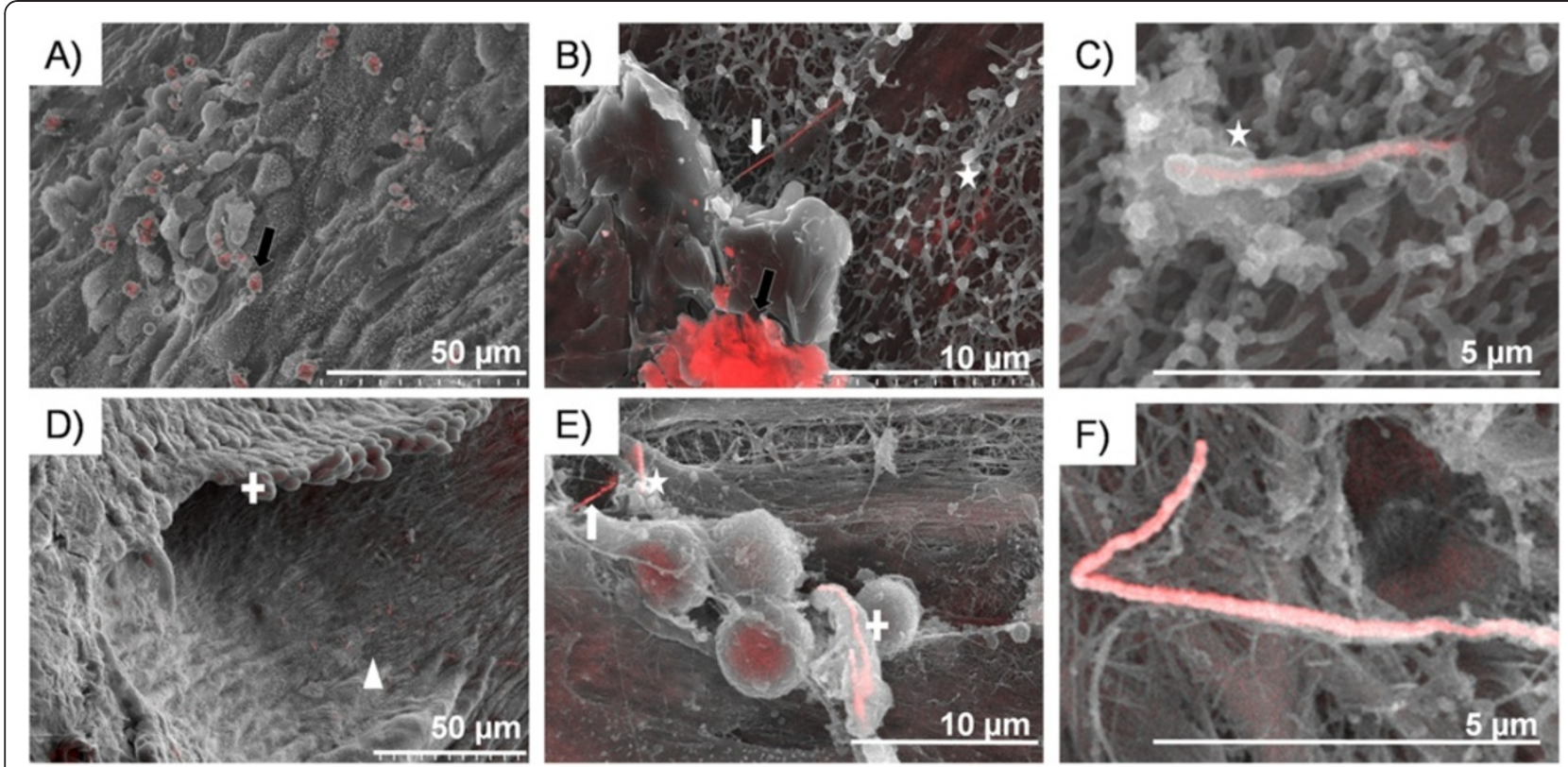

Figure 8 Images of macrophages on the parietal pleura 1 week post pleural instillation of $\mathbf{A g N W}_{\mathbf{5}}$ and $\mathrm{AgNW}_{10}$. Lesion area showing $\mathrm{AgNW}_{5}(\mathbf{A})$ dissolving inside macrophages, as can be seen by the loss of fibre structure (black arrow) (B). Intact nanofibres on the mesothelial cell layer as indicated by the white arrow (B) and membrane bound as indicated by the star (B,C). D) Lesion area appears denser and more granulomatous after 1 week treatment $\mathrm{AgNW}_{10}$ and occasional nanowires can be seen in these granulomatous areas as indicated by the white cross. Surprisingly, a large part of the nanowires were seen on and within the mesothelial cell layer indicated by the triangle. These nanowires appeared structurally intact whereas nanowires fully phagocytosed by macrophages as seen in $\mathbf{E}$ ) indicated by the cross on the right side start to dissolve under the acidic condition within a macrophage. On the top left of this image, a fibre is partly internalised (star) and partly exposed (white arrow). F) $\mathrm{AgNW}_{10}$ which is partly membrane bound on the mesothelial cell layer.

granulomatous after 1 week (Figure $8 \mathrm{D}$ cross), or in the mesothelial cell layer (Figure $8 \mathrm{D}$ triangle). $\mathrm{AgNW}_{10}$ also started to lose integrity inside the phagocytic compartments of pleural macrophages (Figure $8 \mathrm{E}$ cross). Figure $8 \mathrm{~F}$ shows $\mathrm{AgNW}_{10}$ partly membrane bound on the mesothelial cell layer. Data from the same animals as described here were utilised in Schinwald et al. [14].

Compartmentalisation of nanowires into mesothelial cells So far, we hypothesised that after a prolonged exposure to fibres in general up to 7 days, the instilled fibres in the pleural space would either be cleared from the pleural space and enter the lymphatic drainage system or be accumulated in a granulomatous lesion on the parietal pleura at stomata [15]. By using backscatter imaging, for the first time it was possible to visualise nanowires in the mesothelial cell layer of the parietal pleura. Both treatments, $\mathrm{AgNW}_{5}$ and $\mathrm{AgNW}_{10}$ (but not $\mathrm{AgNW}_{3}$ which were not observed as they had been cleared) showed nanofibres either on the surface of the mesothelial cells (black arrow Figure 9B) or taken up by these cells (white arrow Figure 9A,B). This is especially surprising for $\mathrm{AgNW}_{5}$, since pleural macrophages are able to phagocytose these fibres completely as shown in Figure 7B. By comparing the structure/shape of the nanowires associated with the mesothelial layer (Figure 9) and within macrophages (Figure 8B,E), it can quite clearly be seen that the nanowires are still intact after 1 week in the mesothelial layer whereas within the phago-lysosome of a macrophage the fibres start to degrade and lose integrity. These images show evidence that not all fibres longer than $5 \mu \mathrm{m}$ are internalised by macrophages during the early inflammatory reaction, and that some are compartmentalised into the mesothelial layer which could lead to direct effects on the mesothelial cells and pleural diseases in a later stage if they are biopersistent.

\section{Discussion}

The capacity of alveolar macrophages for phagocytosis and clearance of particles and fibres from the lung is of major relevance in pulmonary defence and development of lung and pleural diseases. In this study we addressed the length cut-off value at which frustrated phagocytosis occurs in vitro and in vivo. We recently defined the threshold length for inflammogenicity in the pleural space for a range of fibres including those used here [14]. However in that paper we were unable, due to restrictions on space, to fully explore the role of frustrated phagocytosis nor fully describe the disposition of fibres in the pleural space. In the present paper we were able to quantitatively 

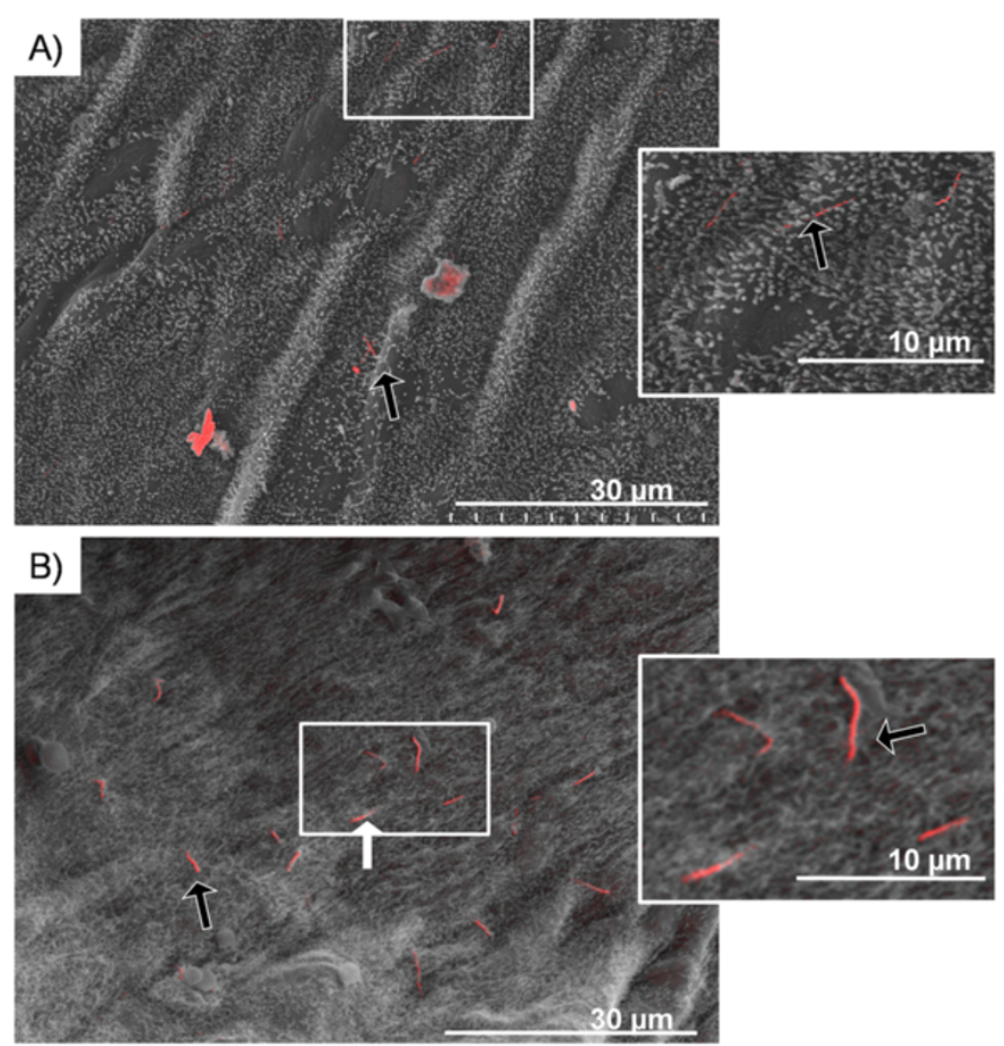

Figure 9 Mesothelial surfaces of the parietal pleura 1 week post injection of $\mathbf{A g N W}_{\mathbf{5}}$ and $\mathbf{A g N W}_{\mathbf{1 0}}$. Mesothelial cell layer of the parietal pleura after $\mathrm{AgNW}_{5}(\mathbf{A})$ and $\mathrm{AgNW}_{10}$ (B) exposure. AgNWs can be seen on the surface of the mesothelial layer as indicated by the black arrow. These AgNW are also partly taken up by mesothelial cells as indicated by the white arrow. The morphology of the nanofibres on the mesothelial layer appears intact.

compare phagocytosis/ frustrated phagocytosis of 5 different lengths of silver nanofibres ranging from $3-28 \mu \mathrm{m}$ where inflammogenicity was determined in a previous study [14]. Thus far, the polydispersity of fibre length in samples including naturally occurring fibres and synthetic vitreous fibres prohibited the accurate investigation of the toxicity of various fibre lengths. The tight length classes of nanofibres used in this study, produced using nanotechnological methods, allowed us to perform a quantitative and qualitative comparison of the role of fibre length and frustrated phagocytosis in vitro and in vivo.

The use of a novel technique, backscatter electron microscopy allowed us to distinguish between membrane bound fibres and unphagocytosed fibres and to visualise the interaction of inflammatory cells with different length of nanofibres on the parietal pleura, the site of fibre retention in vivo.

The need for macrophages to internalise and therefore clear fibres from the lung and the pleural space has long been accepted [16] but the cut-off length below which complete internalisation of particles/fibres occurs is unknown. An extensive study has investigated the phagocytic capacity of murine bone marrow-derived macrophages to engulf various sizes of latex beads in a range of $13 \mu \mathrm{m}$ to $>30 \mu \mathrm{m}$ in diameter [17]. By measuring the bead diameter they calculated a phagocytosis capacity of $19.8 \mu \mathrm{m}$, which is 1.44 times the actual diameter of the cell. In regard to the phagocytosis of fibres by macrophages, Ye et al. investigated the role of glass fibre length in TNF- $\alpha$ production and NF- $\mathrm{KB}$ activation in a mouse macrophage cell line and correlated and increase in both cytokine level and transcription factor to incomplete phagocytosis of long fibres $(17 \mu \mathrm{m})$ whereas short fibres $(7 \mu \mathrm{m})$ were fully phagocytosed and therefore had less expression of the measured endpoints [9]. These data correlate with our identified threshold length for frustrated phagocytosis in vitro, which is $\geq 14 \mu \mathrm{m}$.

An in vivo study performed by Oberdorster et al. assessed the clearance of small $(\sim 3 \mu \mathrm{m}$ in diameter $)$ and large $(\sim 10 \mu \mathrm{m}$ in diameter) polystyrene microspheres in rat and identified minimal clearance of larger spheres after a 200 days post position period [18]. This was considered to be due to impaired clearance of particles when the macrophage particle load is $60 \%$ of its normal volume. 
Frustrated phagocytosis has been implicated to play a major role in the development of an inflammatory milieu after exposure to fibres in vitro $[19,20]$. We recently demonstrated that frustrated phagocytosis is a major factor in the genesis of inflammation in the pleural space after deposition of long fibres whereby macrophages undergoing frustrated phagocytosis of the long fibres release factors that promote a potent pro-inflammatory cytokine response from adjacent mesothelial cells [20]. In addition we have demonstrated that $5 \mu \mathrm{m}$ is the threshold for pro-inflammatory effects of fibre in the pleural space for a wide range of fibers [14]. However, so far frustrated phagocytosis has not been fully visualised in vivo in the pleura and the fibre length threshold for frustrated phagocytosis in vivo is unknown. Here we showed that the length cut off value at which long fibres can be fully phagocytosed by macrophages differs in vitro and in vivo. Whereas in vitro fibres of $10 \mu \mathrm{m}$ could be completely phagocytosed, in vivo inflammatory cells on the parietal pleura showed incomplete uptake and frustrated phagocytosis of $10 \mu \mathrm{m}$ fibres. There are a number of potential explanations for this anomalous difference between in vivo and in vitro length-dependent effect. The in vivo model is a pleural granuloma in mice and this is very different from the in vitro situation. Firstly the cells used in vitro are human cells, secondly they are a cell line and thirdly they are not in the granulomatous milieu but are spread out singly on plastic, submerged in medium with $10 \%$ serum, a very abnormal environment. We conclude that investigations on frustrated phagocytosis and its relation to the pathological effects of fibres need to be carried out in vivo although future work could be focussed on trying different cell lines and culture conditions with the aim of finding a better in vitro model that mimics the in vivo findings.

Interestingly, pleural injection of $\mathrm{AgNW}_{5}$ lead to significant inflammation in the pleural space [14] but was not associated with frustrated phagocytosis in vivo. These results show that frustrated phagocytosis is not solely responsible for the onset of an inflammatory reaction in the pleural space after exposure to fibrous particles and that fibres around $5 \mu \mathrm{m}$ can be fully phagocytosed but nonetheless cause sufficient cellular stress to induce proinflammatory effects (Figure 10).

In this study we focused on the interaction of macrophages with nanofibres, however, our investigations of the parietal pleura revealed that intact nanofibres can also be found on the normal mesothelial cell layer after 1 week exposure. So far, we hypothesised that fibres, which are retained in the pleural space would be accumulated in lesions on the parietal pleura. In our study the mesothelial cells do not seem to be pro-inflammatory in this position as they have not attracted leukocytes to their vicinity and so their main effect may be by direct

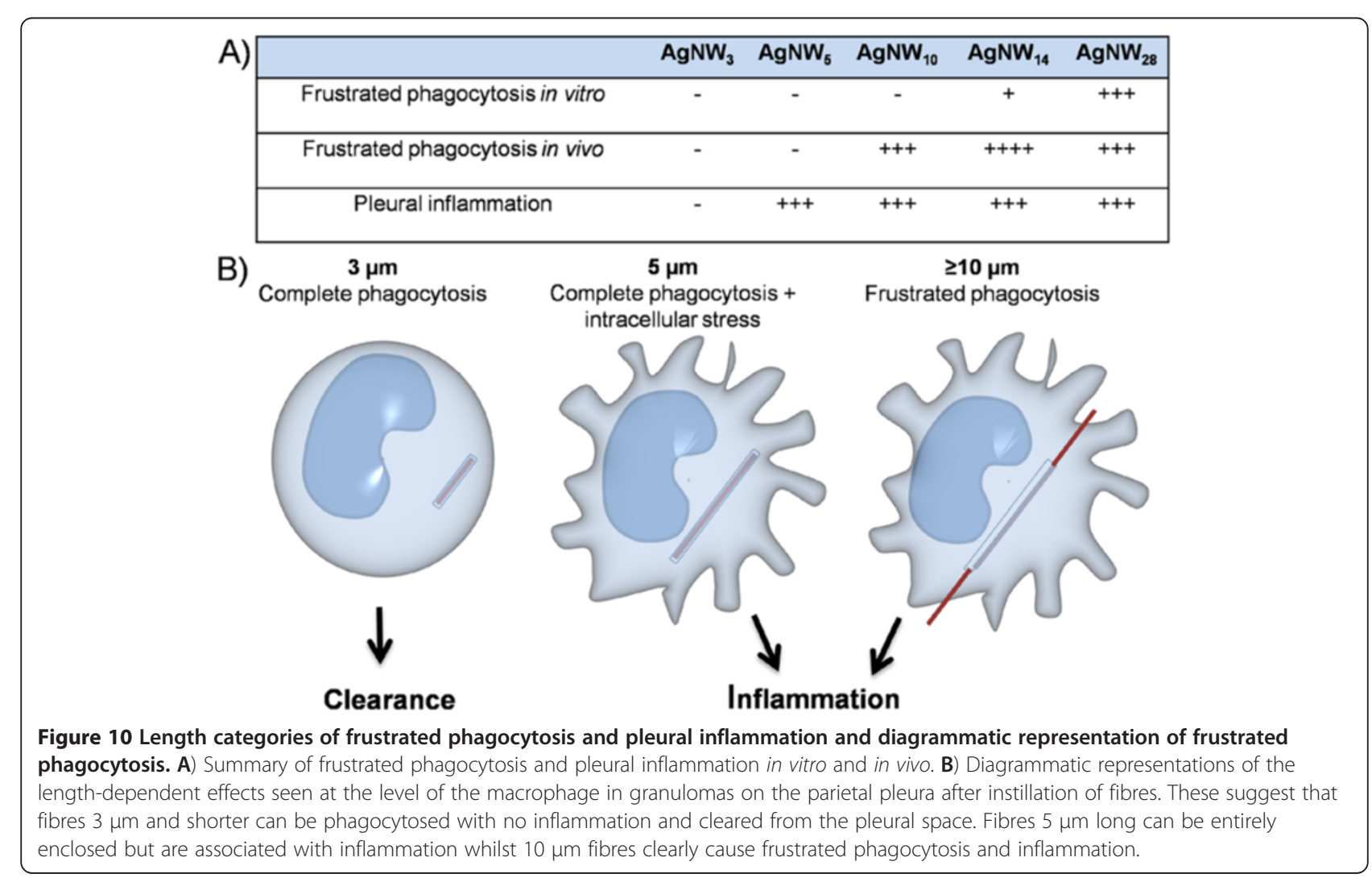


genotoxic or cytotoxic effects on the mesothelial cells. A lack of direct pro-inflammatory effect of the nanowires on the mesothelial cells would be consistent with our recent study on the interactions between long carbon nanotubes, macrophages and mesothelial cells in the genesis of inflammation. Work with long carbon nanotubes show that fibres interacting with macrophages cause the macrophages to release factors that evoke large scale production of inflammatory mediators by adjacent mesothelial cells [20]. Activated mesothelial cells produce a number of pro-inflammatory mediators including prostaglandins, nitric oxide, reactive oxygen species, cytokines and growth factors. Prolonged release of these pro-inflammatory mediators due to retention of fibres on the mesothelial surface may play a role in stimulation of tumour growth [21]. In contrast direct interaction between carbon nanotubes and mesothelial cells in vitro produced very little pro-inflammatory cytokine release by the mesothelial cells but did lead to significant membrane damage at higher carbon nanotube concentrations at a similar extent to that seen in macrophages [20]. A study by Adamson reported that exposure to long $(\leq 20 \mu \mathrm{m})$ crocidolite asbestos fibres lead to increased pleural mesothelial cell proliferation in mice but no uptake of fibres in mesothelial cells was observed and again an indirect effect of mitogens released by cells in the sub-pleural lung tissues was implicated [22].

Therefore nanofibres that escape macrophage phagocytosis and take up residence in the mesothelium may be relatively non-inflammatory but represent a direct genotoxic threat. The interaction of AgNW with mesothelial cells changed their biopersistent characteristics, since AgNW appeared intact in their shape compared to compartmentalisation in macrophages where dissolution is observed. Silver ion measurements may not be helpful in clarifying AgNW persistence either in vivo or in vitro to the complexity of interpreting the data due to silver chloride formation as discussed in Schinwald et al. [14].

Our findings suggest therefore the threshold length of $5 \mu \mathrm{m}$ is a threshold for retention of fibres that has at least 2 sequels:- 1) inflammation in the pleural space ; 2) compartmentalisation and localisation of such fibres to the mesothelial layer.

\section{Conclusion}

The use of backscatter scanning electron microscopy enabled us to identifying frustrated phagocytosis in vitro and in vivo using metal-based nanofibre samples without the further need of nanofibre modification including radio labelling or fluorescence labelling to visualise their interaction with cells and tissue. The images and data provided in this study show a clear cut-off value for frustrated phagocytosis in vitro and in vivo (Figure 10). We could visualise the interaction of nanowires with pleural inflammatory cells in vivo and revealed that frustrated phagocytosis is not the only factor for the onset of pleural inflammation and $5 \mu \mathrm{m}$ fibres can be fully enclosed but are still associated with inflammation as previously described [14]. The contrast between the in vitro and in vivo finding for the length threshold for frustrated phagocytosis suggest that THP-1 macrophages do not provide a good model for the length dependent phagocytic events that occur in vivo in the murine pleural space. More research may provide a better in vitro model that mimics the in vivo effects. We also visualised the interaction of mesothelial cells with nanofibres and described a novel compartmentalisation of them in mesothelial cells which appeared to show different biopersistence characteristics compared to compartmentalisation in macrophages. However this needs to be confirmed by more quantitative studies rather than the merely descriptive data that are presented here.

\section{Materials and methods \\ Backscatter electron signals by scanning electron microscopy}

Elements with high atomic number $(Z)$ such as silver reflect or back-scatter electrons more strongly than the lower $Z$ light elements (predominantly $\mathrm{H}, \mathrm{C}, \mathrm{N}, \mathrm{O}, \mathrm{P}$ ) of which cells are composed. Back-scattered electron imaging (BSE) is therefore a useful way to study frustrated phagocytosis since it provides high-contrast detection of nanowires, allowing clear discrimination between the nanofibres and other cellular features. Since the BSE signal from the fibres is attenuated by overlying cellular material, the method allows a clear distinction to be made between fibres that are, or are not, membrane-bounded, and can allow detection of fully phagocytosed fibres, which would not otherwise be detected in an SE image, provided they are at shallow depth within the cell.

This principle has been used widely for detection of colloidal gold markers in immunocytochemistry [23,24].

\section{Fibre panel and size distribution}

The fibre panel consisted of five distinct length classes of silver nanowires, hereafter referred to as $\mathrm{AgNW}_{3}, \mathrm{AgNW}_{5}$, $\mathrm{AgNW}_{10}, \mathrm{AgNW}_{14}$ and $\mathrm{AgNW}_{28}$ whereby the subscript numbers indicate the average length of the nanowires. AgNW length diameter, contamination, soluble metal content, endotoxin level and dispertion was characterised as described previously by Schinwald et al. [14] (Figure 2). The samples were kindly provided by Seashell Technology, San Diego and synthesised using a polyol process as decribed in the US patent number 7,922,787 B2.

For light microscopy images $1 \mathrm{mg} / \mathrm{ml}$ of AgNWs were dispersed in $0.5 \%$ bovine serum albumin (BSA; Sigma-Aldrich, Poole, UK) and $10 \mu \mathrm{l}$ of suspension was mixed in equal 
volume of glycerol (Sigma-Aldrich, Poole, UK) to reduce the flow of AgNW. The suspension was placed on a glass slide, covered with coverslip and images taken using QCapture Pro software (Media Cybernetics).

\section{In vitro study}

In vitro macrophages exposed to fibres of different lengths

Cell culture The immortalised human monocytic cell line THP1 was used for in vitro studies. Cells were cultured in RPMI media supplemented with $10 \%$ heat inactivated FBS, 1\% penicillin/streptomycin and 1\% L-Glutamine (PAA, Austria). Prior to each treatment the cells were seeded in 24-well plates at a density of $0.5^{*} 10^{6} / \mathrm{ml}$ in $500 \mu \mathrm{l}$ medium containing $10 \% \mathrm{FBS}$ and $10 \mathrm{ng} / \mathrm{ml}$ phorbol 12-myristate 13-acetate (PMA) (Sigma) for 2 days at $37^{\circ} \mathrm{C}$ in $5 \% \mathrm{CO}_{2}$ atmosphere [25]. Fibres were uniformly dispersed in cell culture medium (RPMI 1640) supplemented with $1 \%$ penicillin/streptomycin and $1 \%$ L-Glutamine (PAA, Austria) and $0.5 \%$ bovine serum albumin (BSA; Sigma-Aldrich, Poole, UK) and briefly vortexed. Cells were treated with AgNW equalised to fibre number since fibre exposure is regulated on the basis of the fibre number and so relative potency needs to be determined on a per-fibre basis. To equalise for fibre number a dose of $2 \mu \mathrm{g} / \mathrm{cm}^{2}$ for $\mathrm{AgNW}_{14}$ was chosen as the standard in vitro dose based on previous measurement of membrane integrity and proliferation. Based on $2 \mu \mathrm{g} / \mathrm{cm}^{2}$ for $\mathrm{AgNW}_{14}$, concentrations for the other length classes AgNW panel were calculated assuming that fibres thickness was constant in the different length classes (Table 1).

\section{Measurement of membrane integrity and proliferation of THP-1}

Cells were seeded at a concentration of $0.5^{*} 10^{6}$ cells $/ \mathrm{ml}$ and treated for 24 hours as described above. TritonX (Sigma) was used as a positive control for cell death and was added at a final concentration of $0.1 \%$ for 30 mins. After the treatment supernatant was centrifuged for $5 \mathrm{mins}$ at $2000 \mathrm{rpm}$, transferred and centrifuged again for $5 \mathrm{mins}$ at $13000 \mathrm{rpm}$. The conversion of lactate to pyruvate was detected using the Cytotoxicity Detection Lactate Dehydrogenase kit (Roche Diagnostics Ltd., Burgess Hill, UK) following the manufacturer's instructions. A microplate reader $\left(\right.$ BioTek $^{\oplus}$ SynergyHT) was used to measure the optical density at $490 \mathrm{~nm}$. Results are given as the mean \pm SEM of 5 independent experiments.

Cells in the culture dish were used to measure their proliferation and metabolic activity via a chemical reduction of AlamarBlue ${ }^{\bullet}$ (Invitrogen). $150 \mu \mathrm{l}$ of PBS and $15 \mu \mathrm{l}$ of AlamarBlue ${ }^{\oplus}$ was added to each well and incubated for 3 hours at $37^{\circ} \mathrm{C}$ in $5 \% \mathrm{CO}_{2}$ atmosphere. Absorbance was monitored at $570 \mathrm{~nm}$ and $600 \mathrm{~nm}$ as a reference wavelength. Data are normalized to $600 \mathrm{~nm}$ value. Results are given as the mean \pm SEM of 5 independent experiments.

\section{Preparation for BSE}

THP-1 cells were differentiated as described above and seeded into 24 well plates on Thermanox ${ }^{\bullet}$ Plastic Coverslips $\left(\mathrm{NUNC}^{\mathrm{TM}}\right.$, Rochester, NY USA) at a density of $0.5^{*} 10^{6} / \mathrm{ml}$. The cells were treated for 4 hours using concentration as described above at $37^{\circ} \mathrm{C}$ in $5 \% \mathrm{CO}_{2}$ atmosphere. After the treatment they were washed $5 \times$ with $0.1 \mathrm{M}$ sodium cacodylate ( $\mathrm{pH} 7.2$ ) buffer. Overnight fixation was done in 3\% glutaraldehyde/ $0.1 \mathrm{M}$ sodium cacodylate ( $\mathrm{pH}$ 7.2) buffer. After fixation the cells adherent to the coverslips were washed three times in sodium cacodylate buffer.

\section{Bright field microscopy}

THP-1 cells were differentiated as described above in a $\mu$-dish (35 mm) (ibidi, Germany) and treated for 4 hours as described above. Brightfield microscope images were taken using Leica confocal laser scanning microscope SP5 at a $60 \times$ oil immersion objective lens.

\section{In vivo study}

\section{Intra pleural injection of fibres}

Fibres were uniformly dispersed in $0.5 \%$ bovine serum albumin (BSA; Sigma-Aldrich, Poole, UK)/saline at a concentration of $50 \mu \mathrm{g} / \mathrm{ml}$ which equates a dose of $5 \mu \mathrm{g}$ per mouse and injected into the pleural cavity of female C57BI/6 mice (aged 8 weeks) at a volume of $100 \mu \mathrm{l}$ per mouse as described previously by Schinwald et al. [14]. We used a sleeve close to the tip of a $27 \mathrm{G}$ needle to prevent it penetrating beyond the pleural space into the lung [13]. Mice were euthanized after 24 hours $(n=4)$ and 7 days $(n=4)$ by asphyxiation in $100 \% \mathrm{CO}_{2}$.

\section{Lavage of pleural space}

The pleural space was lavaged with three $1 \mathrm{ml}$ washes of sterile saline and kept on ice. To separate the cellular fraction from the supernatant the lavage fluid was centrifuged for 5 minutes at $2000 \mathrm{rpm}$ at $4^{\circ} \mathrm{C}$ in a Mistral 3000i centrifuge (Thermo Fisher Scientific, Inc., MA, USA). Cyto-centrifugation with following Diff-Quik staining using Diff-Quik stainset (Dade Behring Gmbh, Marburg, Germany) were prepared for visualising uptake of fibres in pleural macrophages.

\section{Preparation parietal pleura for BSE Tissue dissection}

The lower right posterior portion of the chest wall, approximately an area of $1 \mathrm{~cm} \times 0.5 \mathrm{~cm}$ along the spine was cut out from the mice after lavage, washed in icecold saline and fixed for 4 hours in $30 \%$ formalin. The 
tissue was excised from the surrounding tissue and fixed with $3 \%$ glutaraldehyde in $0.1 \mathrm{M}$ Sodium Cacodylate buffer ( $\mathrm{pH}$ 7.3) for 3 hours then washed in three 10 minute changes of 0.1 M Sodium Cacodylate buffer.

\section{Cell and tissue preparation for BSE}

Fixed samples were dehydrated in 50\%, 70\%, 90\% and $100 \%$ normal grade acetones for 10 minutes each, then for a further two 10-minute changes in analar acetone. Dehydrated samples were critical point dried and mounted on SEM aliminium stubs and rotary-coated with about $8 \mathrm{~nm}$ of carbon in an Edwards 306A vacuum coating system (Edwards High Vacuum, Crawley, UK).

\section{BSE}

SEM of carbon-coated specimens was carried out using a Hitachi 4700 II field emission SEM (Hitachi HighTech, Maidenhead, UK) at a beam accelerating voltage of $10 \mathrm{kV}$ and a working distance of about $8 \mathrm{~mm}$. Secondary electron (SE) and BSE images were taken simultaneously using an annular YAG crystal BSE detector and the upper SE detector to produce perfectlysynchronised image pairs. The two images were superimposed using Adobe Photoshop. The SE and BSE image were converted to grayscale, the BSE image was pasted into the SE image by using the layer function "lighten". This newly merged image and the SE image were converted to RGB mode, and overlayed by pasting the red channel of the BSE image into the red channel of the greyscale SE image, thus colour coding in red the strong BSE signal from the nanowires, the SE image appearing in grey.

\section{Methodology for quantifying unphagocytosed fibres}

Image-Pro plus software (Media Cybernetics Inc., MD, USA) was used to measure the amount AgNW outside macrophages. The intensity of red pixels of the nanofibres differs if the fibre is taken up by a cell and therefore covered by a cell layer (lower intensity) or if the fibres is unphagocytosed (higher intensity). Using Image-Pro software, it was possible to specifically select the red pixel intensity of unphagocytosed cells which was expressed as object and area count. The number of objects (unphagocytosed fibres) was divided by the number of cells per image and expressed as unphagocytosed fibres per cell. Approximately 100 cells per image were counted $(n=3)$.

\section{Statistical analysis}

All data are shown as the mean \pm s.e.m. and these were analysed using one-way analysis of variance (ANOVA). Multiple comparison were analysed using Tukey-HSD method and in all cases (GraphPad InStat Software Inc., CA, USA).

\section{Abbreviations}

AgNW: Silver Nanowires; NiNW: Nickel nanowires; BSM: Backscatter scanning electron microscopy; LDH: Lactate dehydrogenase.

\section{Competing interests}

The authors declare that they have no competing interests.

\section{Authors' contributions}

A.S. conceived and designed the experiments, analysed the data and wrote the manuscript. K.D. initiated the study, oversaw all experimental work and contributed to manuscript preparation. All authors read and approved the final manuscript.

\section{Acknowledgements}

We thank Chris Jeffree for specialist input in BSM and S. Mitchell (University of Edinburgh) for sample preparation for SEM and technical assistance and the Colt Foundation (A.S., K.D) for financial support. We also thank James R. Glass, Janet C. Dickerson and David A. Schultz from Seashell Technology for providing the AgNW samples.

Received: 14 May 2012 Accepted: 15 August 2012

Published: 28 August 2012

\section{References}

1. Kamp DW: Asbestos-induced lung diseases: an update. Trans/ Res 2009 153:143-152.

2. Warheit DB, Driscoll KE, Oberdoerster G, Walker C, Kuschner M, Hesterberg TW: Contemporary issues in fiber toxicology. Fundam App/ Toxicol 1995, 25:171-183.

3. Donaldson $\mathrm{K}$ : The inhalation toxicology of $\mathrm{p}$-aramid fibrils. Crit Rev Toxicol 2009, 39:487-500.

4. Donaldson K, Murphy FA, Duffin R, Poland CA: Asbestos, carbon nanotubes and the pleural mesothelium: a review of the hypothesis regarding the role of long fibre retention in the parietal pleura, inflammation and mesothelioma. Particle and Fibre Toxicology 2010, 7:5.

5. Donaldson K, Murphy F, Schinwald A, Duffin R, Poland CA: Identifying the pulmonary hazard of high aspect ratio nanoparticles to enable their safety-by-design. Nanomedicine (Lond) 2011, 6:143-156.

6. Wright GW, Kuschner M: The influence of varying lengths of glass and asbestos fibres on tissue response in guinea pigs. Inhaled Part 1975, 4(Pt 2):455-744. 455-474.

7. Davis JM, Addison J, Bolton RE, Donaldson K, Jones AD, Smith T: The pathogenicity of long versus short fibre samples of amosite asbestos administered to rats by inhalation and intraperitoneal injection. Br J Exp Pathol 1986, 67:415-430.

8. Donaldson K, Brown GM, Brown DM, Bolton RE, Davis JM: Inflammation generating potential of long and short fibre amosite asbestos samples. Br J Ind Med 1989, 46:271-276.

9. Ye J, Shi $X$, Jones W, Rojanasakul Y, Cheng N, Schwegler-Berry D, et al: Critical role of glass fiber length in TNF-alpha production and transcription factor activation in macrophages. Am J Physiol 1999, 276:L426-L434.

10. Donaldson K, Li XY, Dogra S, Miller BG, Brown GM: Asbestos-stimulated tumour necrosis factor release from alveolar macrophages depends on fibre length and opsonization. J Pathol 1992, 168:243-248.

11. Poland CA, Byrne F, Cho WS, Prina-Mello A, Murphy FA, Davies GL, et al: Length-dependent pathogenic effects of nickel nanowires in the lungs and the peritoneal cavity. Nanotoxicology 2011, [Epub ahead of print].

12. Poland CA, Duffin R, Kinloch I, Maynard A, Wallace WA, Seaton A, et al: Carbon nanotubes introduced into the abdominal cavity of mice show asbestos-like pathogenicity in a pilot study. Nat Nanotechnol 2008 3:423-428.

13. Murphy FA, Poland CA, Rodger D, Al-Jamal KT, Hanene A-B, Antonio N, et al: Length-dependent retention of carbon nanotubes in the pleural space of mice initiates sustained inflammation and progressive fibrosis on the parietal pleura. Am J Pathol 2011, 178:2587-2600.

14. Schinwald A, Murphy F, Prina-Mello A, Poland CA, Byrne F, Glass JR, et a: The threshold length for fibre-induced acute pleural inflammation: shedding light on the early events in asbestos-induced mesothelioma. Toxicol Sci 2012, Ref Type: In Press. 
15. Boutin C, Dumortier P, Rey F, Viallat JR, De Vuyst P: Black spots concentrate oncogenic asbestos fibers in the parietal pleura. Thoracoscopic and mineralogic study. Am J Respir Crit Care Med 1996, 153:444-449.

16. Lehnert BE: Pulmonary and thoracic macrophage subpopulations and clearance of particles from the lung. Environ Health Perspect 1992, 97:17-46.

17. Cannon GJ, Swanson JA: The macrophage capacity for phagocytosis. J Cell Sci 1992, 101:907-913.

18. Oberdorster G, Ferin J, Morse P, Corson NM, Morrow PE: Volumetric alveolar macrophage (AM) burden as a mechanism of impaired AM mediated particle clearance during chronic dust overloading of the lung. J Aerosol Med 1988, 1:A207.

19. Brown DM, Kinloch IA, Bangert U, Windle AH, Walter DM, Walker GS, et al: $\mathrm{An}$ in vitro study of the potential of carbon nanotubes and nanofibres to induce inflammatory mediators and frustrated phagocytosis. Carbon 2007, 45:1743-1756.

20. Murphy FA, Schinwald A, Poland CA, Donaldson K: The mechanism of pleural inflammation by long carbon nanotubes: interaction of long fibres with macrophages stimulates them to amplify pro-inflammatory responses in mesothelial cells. Part Fibre Toxicol 2012, 9:8.

21. Mutsaers SE: Mesothelial cells: their structure, function and role in serosal repair. Respirology 2002, 7:171-191.

22. Adamson IR: Early mesothelial cell proliferation after asbestos exposure: In vivo and in vitro studies. Environ Health Perspect 1997, 105:1205-1208.

23. Soligo D, de Harven E, Nava MT, Lambertenghi-Deliliers G, Müeller M, Becker RP, Boyde A, Wolosewick JJ: Immunocytochemistry with back-scattered electron. In The science of Biological specimen preparation for microscopy and microanalysis. In Scanning Microscopy; 1985:289-297.

24. Jeffree CE, Rixon HW, Brown G, Aitken J, Sugrue RJ: Distribution of the attachment (G) glycoprotein and GM1 within the envelope of mature respiratory syncytial virus filaments revealed using field emission scanning electron microscopy. Virology 2003, 306:254-267.

25. Park EK, Jung HS, Yang HI, Yoo MC, Kim C, Kim KS: Optimized THP-1 differentiation is required for the detection of responses to weak stimuli. Inflamm Res 2007, 56:45-50.

doi:10.1186/1743-8977-9-34

Cite this article as: Schinwald and Donaldson: Use of back-scatter electron signals to visualise cell/nanowires interactions in vitro and in vivo; frustrated phagocytosis of long fibres in macrophages and compartmentalisation in mesothelial cells in vivo. Particle and Fibre Toxicology 2012 9:34.

\section{Submit your next manuscript to BioMed Central and take full advantage of:}

- Convenient online submission

- Thorough peer review

- No space constraints or color figure charges

- Immediate publication on acceptance

- Inclusion in PubMed, CAS, Scopus and Google Scholar

- Research which is freely available for redistribution 